\title{
REVITALISING COMMUNITY-BASED TOURISM - CRITICAL SUCCESS FACTORS
}

\author{
Nor Haniza Mohamad ${ }^{1}$ \\ Zainab Khalifah ${ }^{2}$
}

\begin{abstract}
Community-based tourism projects are often criticised for its high rate of failure but some are very successful.The primary aim of this study is to investigate the Critical Success Factors (CSF) of a community-based tourism (CBT) project from the perspective of local community. This study used a qualitative approach through a single case to investigate a CBT project in BatuPuteh, Kinabatangan in the state of Sabah. Five fieldwork trips were made to collect data between the years 2010 to 2012. Multiple instruments were used to collect data; in-depth interview (main research instrument), and direct observation and document analysis (supporting instruments). 54 respondents that were/are employed by MESCOT on a full-time and part-time basis were identified through nonprobability purposive sampling technique and subsequently interviewed. Recorded interviews were transcribed and then analysed using thematic analysis. The findings revealed that there are prominent CSF attributable to the success of CBT at the study site; iconic natural resources, external initiator, systematic planning, local champion, community participation, local CBT organization, gestation period, partnership with external agencies, and business model. Partnerships between CBT and government or non-government agencies are crucial throughout the lifecycle of CBT. Equally important, this study shows that CSFs are presentable in temporal form; each factor exists / occurs at a particular stage of the development path of CBT. However, a few critical factors are ubiquitous throughout the different stages of the product life cycle. Although the case study referred to a single CBT organization in Malaysia, the findings substantiate that an effective model for CBT is achievable, replicable and applicable to other places with similar enabling environments.
\end{abstract}

Key words: community-based tourism, critical success factors, iconic natural resources, external initiator, systematic planning, local champion, community participation, local CBT organization, gestation period, partnership with external agencies, and business model

\section{INTRODUCTION}

\section{RevitalisingRural Economy through Community Based Tourism}

In many developing countries, community-based tourism (CBT) is commonly chosen as a'low-capital, high yield'strategy to revitalize rural economy (Gunduz and Hatemi-J, 2005; Briedenhann and Wickens, 2004; MacDonald and Joliffe, 2003; Sharpley, 2002; Tooman, 1997; Hjalager, 1996) by tapping on tourists desire to see the haves not. CBT can be generally described as profit-oriented tourism activity, project or enterprise that is based on local socio-cultural/heritage, natural resources and attractions located on the local community's land or its vicinity, which involves local community as managers or/and operators.

More often than not, Community Based Tourism (CBT) is regarded as a panacea for rural poverty given that CBT is often perceived as being small scale, low density, low impact, controlled by the local community and generates direct economic benefits to the community. What is becoming standard practice especially in developing countries is the

\footnotetext{
${ }^{1}$ Principal Lecturer, Department of Tourism and Hospitality, Politeknik Ibrahim Sultan, Pasir Gudang, Malaysia.

${ }^{2}$ Professor, Faculty of Management, University Teknologi Malaysia, Johor Bahru, Malaysia.
} 
almost uncritical acceptance of CBT as the source of livelihood for local communities living within or surrounding protected areas. However, several researches have revealed that CBT despite the nature of the project is relatively easy to start but difficult to sustain and sometimes fail to generate significant economic benefits for the local people (Friederike Luck, 2010; Ghasemi and Hamzah, 2010; Hamzah, 2010; Goodwin and Santilli, 2009; Hamzah and Khalifah, 2009; Goodwin, 2006).

In a nutshell, previous studies have discussed critical factors that contributed to the failure or success of CBT programmes particularly from the perspectives of CBT managers and experts. However, the views of the local community on what makes a CBT successful were understudied despite them being a central component of CBT. The lack of insights from the locals' point of view as the main driver of any CBT could lead to premature interpretation of CSF and thus a mismatch with strategic planning efforts. This paper explains why and how CBT projects in Malaysian can succeed by investigating the critical success factors using a successful conservation-based CBT called Miso Walai Homestay (MWH) located in Kinabatangan, Sabah for contextual setting.

\section{LITERATURE REVIEW}

Some researchers have criticised community-based tourism for failing to deliver significant economic, socio-cultural or environmental impacts (Goodwin and Santilli, 2009; Harrison, 2008; Blackstock, 2005; Clauzel, 2001; Brockelman, 1988). A few researches have revealed that CBT are unsuccessful due to local community's over dependency on donor agency (Kiss, 2004); rivalry with dominant forms of tourism development (Renard, 2001);overwhelming negative impacts (Moscardo, 2005); low tourist arrivals (Responsible Travel.com and Conservation International, 2006); over dependency on donor fund (Mitchell and Muckosy; 2008); propagation of a handout mentality, lack of adequate markets, and vague definition of CBT (Goodwin and Santilli, 2009); absence of genuine CBT local champion (Federico, 2009); and narrow income distribution among community members (Blackstock, 2005;Belsky, 1999).

\section{METHODOLOGY}

Five fieldwork trips were made to collect data between the years 2010 to 2012. Multiple instruments were used to collect data; in-depth interview (main research instrument), and direct observation and document analysis (supporting instruments). 54 respondents that were/are employed by MESCOT, the team which manages $\mathrm{MWH}$, on a full-time and parttime basis were identified through non-probability purposive sampling technique and subsequently interviewed. Recorded interviews were transcribed and then analysed using thematic analysis based on the critical success factor themes gathered from literature review.

\section{FINDINGS AND DISCUSSION}

\section{Broad-based Local CBT Organization}

Local CBT organization refers to a body, which manages and operates the CBT programme on a daily basis.Community cooperative is a form of a broad-based organization that can be used as a business model to run a CBT project. It is deemed as better able to protect the 
interests of its members through the provisions of a supportive legal framework. MWH is run by a broad-based local CBT organization/community cooperative which is closely associated to its success. A cooperative business model has several merits which fit into the nature of the CBT project: enables the local people who are its shareholders to decide the future of CBT;ability to curb potential manipulation from local elites; ensure accountability and transparency of CBT's operations and in redistribution of income; 'legalising' a CBT initiative by putting it as a cooperative's business unit.Thisgradually pushesthe outright resistance from the local peopleto the background and subsequently expedites the 'buy-in' processfromthe local community.However, continuous communication to the local community through various means (community leader, meeting, CBT bulletin, social conversation) proved to be effective in expediting community buy-in, although the process is slow.

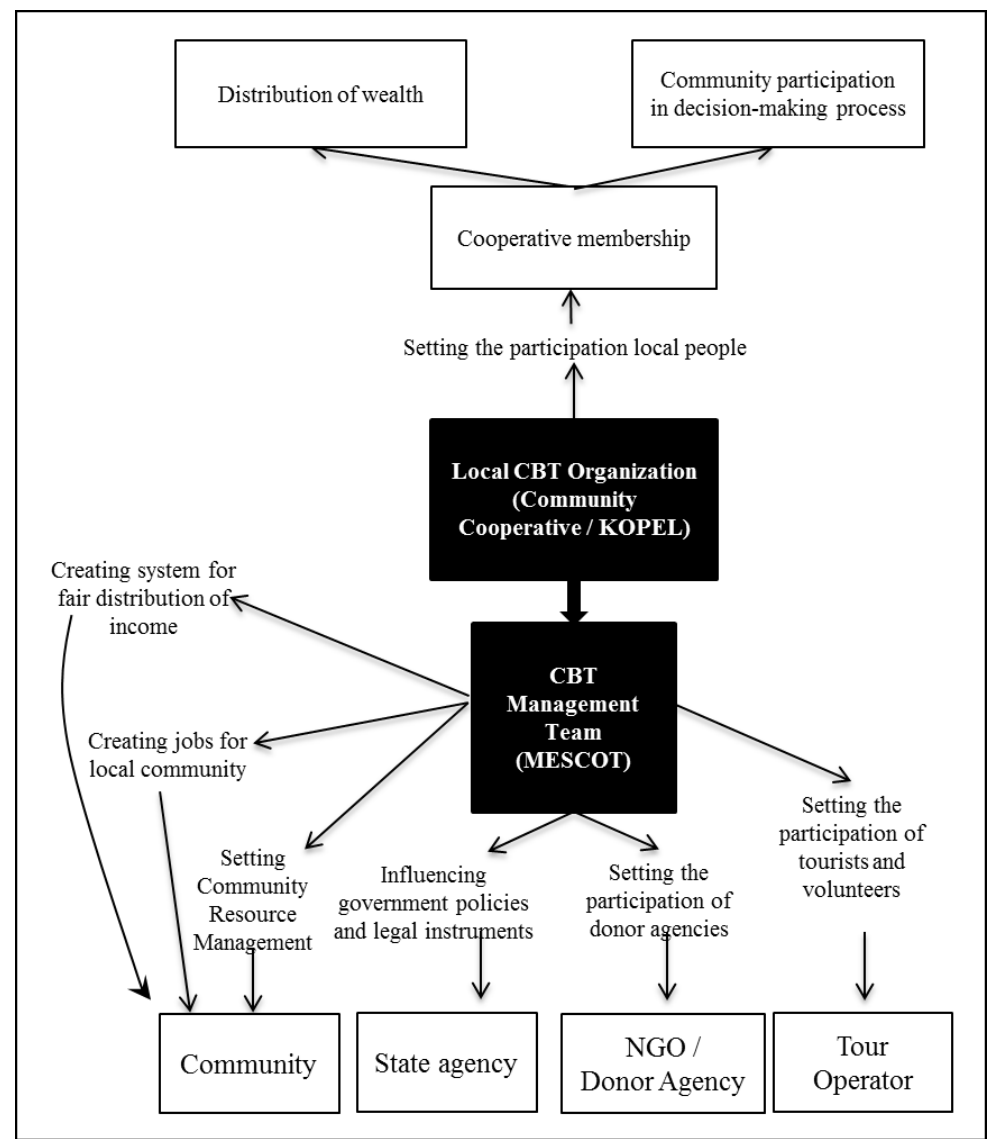

Fig. 1. Strengthening CBT organization through community cooperative Source: Researcher, 2014

It is cautioned that adopting cooperative business model does not promise sustainable success. When a community establishes a cooperative, its board of directors is obliged to create economic activities that benefit its members. However, running a business may be quite challenging for a rural community. Sometimes community cooperative is established but the cooperative is not ready in terms of capital to finance its economic activities. In addition, rural communities tend to have higher composition of older people who naturally 
have limited capacity due to the age factor and this can undoubtedly limit their commitment in any economic ventures. The various conditions related to the establishment and sustainability of a community cooperative are probably overwhelming which have resulted in the sluggish adoption of a cooperative business model by CBT communities. Therefore, it is not overemphasizing to say that CBT project demands people with the right vision, mind-set, attitude, knowledge and skills; sound planning and implementation blueprint; strong financial assistance; and viable CBT economic activities.Fig. 1.shows the interactions between a community cooperative and its CBT business unit based on MHW experience

\section{CBT Leaders}

Another important finding of this study revolves around the roles of CBT leaders. The findings of the study contribute insights towards a better understanding of laudable traits and values of CBT leaders, local or non-local, who manage a CBT project.

The importance of CBT leaders and leadership is evidenced by APEC study that focussed on best practices of ten modelsof community based tourism projects in Asia-Pacific regions (Hamzah\&Khalifah, 2009) which surmised that almost all successful CBTs were initiated by outsiders such as donors/NGOs, government agencies and the private sector, and championed by local leaders. The finding in MWH concurs with the APEC study. The development of the physical aspects of CBT projects must go in tandem with the development of CBT leaders/local champions. The presence or the lack of leadership decides the fate of the project. In MWH case, respondents' emphasized on the role of external project initiator in the success of the MWH CBT program which underlines the importance of visionary and capable leaders particularly in the early stage of CBT development. If the leader is an outsider, it is essential that his personal characteristics, leadership orientation, knowledge and skills are compatible with the community's values and needs. These enable the external leader to be generally accepted by the local people into their community and culture.

In cases where external leaders prominently lead CBT during incubation period, local champions have to be groomed as second line of leaders to eventually take the baton from the external leaders. External leader will leave the project when his/her contract expires which makes the presence and role of a local champion imperative. The mere presence of a local champion in a CBT project is not enough. A local champion must demonstrate leadership attributes and values that can professionally bring the CBT project forward. Hamzah and Khalifah (2009) who studied ten successful CBT projects in Asia Pacific region pointed out in their study that attributes of a 'local champion' include trustworthiness, perseverance, selflessness, patience, good communicator, disciplined, resourceful, visionary, proactive, courageous, and sensible. MWH leaders possess these traits and values. It is worth pointing out that social capital, social hierarchy and knowledge are useful assets to a local champion. A local personwho is prominent, has higher social hierarchy and extensive blood ties within the local community, and knowledgeablecan usually be a strong leader.

\section{Incubation Timeframe}

Another interesting finding that can be considered as practical contribution is pertinent to the issue of gestation period of CBT projects. UNDP recommends a five-year gestation 
period for community-based projects to achieve maturity (Moeurnet al. 2008) but this duration is refuted by some quarters claiming that it is inadequate.MWH experience reveals the necessity to have a stretched incubation period to accommodate the learning curve of the local people who were directly involved in the process of developing MHW CBT project.

In CBT practise, it is common for donor agencies to initiate, develop and fund a CBT project in a rural area for duration of three to five years, after which the donor agencies or management team will leave the projects due to expired contracts or dried up funds. This 'incubation' period serves as a trial period for the local community to learn all the ropes of the trade so that they are able to take up the project on their own when external agencies leave. The three to five-year duration of incubation period, common to other non-CBT businesses, is deemed to be adequate to prepare the local community to run CBT project on their own when the donor agencies leave. However, many CBT projects have shown that such incubation period is inadequate to prepare the local people with the knowledge and skills to manage and operate a CBT project. Many communities needed a longer incubation period. For example, the incubation period for a CBT project in Simango, Zambia was ten years (Sakala, 2004). MWH took almost fourteen years to break away from being highly dependent on donor agencies for financial support and technical assistance.

Donor/charity agencies, government agencies, and corporations need to revise their involvement in CBT projects. Communities involved in CBT projects are known to have a long learning curve, exceeding the usual three to five years incubation window. Sometimes what happen is that all the necessary ingredients for a successful CBT recipe are there such as the potentials anddesire to succeed. However, there is just a huge gap between NGO thinking, corporate thinking, government thinking, and what the needs of the community are. Stakeholders must thoroughly listen to the local people, consider the local community's relationship with the land and their development agenda. The shortcoming of involving NGO, government, or industry sometimes stems from their need for publicity. Therefore, instead of imposing ideas on the local community, external agencies should believe that the local people have some wisdom on the ground. Perhaps, the new thinking that should be adopted by donor agencies is to grow with the local community, and acknowledge that the learning curve of a community differs from one another. Donor agencies that want to commit to a community project have to follow through the community's learning process. A longer gestation period will have a better impact on some local communities who may need an extended learning curve.

\section{Capacity Building}

Another practical contribution of this study concerns the capacity building process. Continuous capacity building process that takes place throughout the CBT life cycle is essentially significant. MWH experience contributes to the understanding of capacity building in CBT project.

It is emphasized that the development of the physical aspects of CBT projects must go in tandem with capacity building programmes for the local community to participate effectively in CBT projects. Capacity building enables rural communities to participate in rural tourism activities (Forstner, 2004). In many instances, CBT projects gradually falter after the donor agencies left. This is associated with the local community's over reliance on the donor agency/NGO for financial support and technical assistance which resulted in 
underdevelopment of tourism related knowledge and skills among the local community. Due to the over reliance on outside help, the local community's limited capacity could not prepare them to take over the management and operation of their own CBT projects. This issue was poignantly evident as in the case of CBT projects in Cambodia, where economic crisis in Europe had forced the Dutch donor SNV to abandon their projects due to the abrupt termination of funding (Baromey et al., 2011).

The failure of local community to take part in CBT project at managerial level or operational level is their over-reliance on donors for financial support and technical expertise which resulted in a 'hand out mentality' (Hamzah\&Khalifah, 2009). This can negatively affect the local community's ability to plan, monitor and operate their CBT project when the donor agencies leave. Hall (2005) associated the failure of community members to capitalize on the opportunities arising from the development due to the lack of awareness and understanding the cause for the tourism development. However, contradictory to common practices in unsuccessful CBT projects, MWH puts great emphasis on building the capacity of the local people from the start of the project to make sure they can meaningfully participate in CBT activities.MWH had taken a dynamic approach in building the capacity of the local people through a systematic plan. The first three years was deemed as the most crucial period of capacity building process. The management team built the capacity of its members for three years from 1996 until 1999 to increase awareness, knowledge and skills of the community. The success ofMWH has always been associated with this long process of capacity building that had empowered the local people with the needed attitude, skills and knowledge to embrace change.

At the beginning of the project, MWH management team painstakingly invested substantial efforts in strengthening community's awareness, knowledge and skills, built through formal and informal learning activities, which enable those directly involved in CBT to understand and appreciate quality tourism product and services. Experiential learning process was used where CBT employees went on trips to visit top-ranked tourism attraction sites and service providers to experience these products and services so that they can understand the meaning of quality tourism products and services. The participants claimed that these activities were significant; they were 'eye-openers' particularly for those who had never had the opportunities visiting well-known attraction sites and outstanding services. Gradually, their understanding and appreciation of quality, knowledge, and skills improved through continuous capacity building programmes.Similarly, other CBT projects should also adopt experiential learning in their capacity building programmes. Fig. 2.depicts the process and main components of capacity building programme.

Despite efforts and resources allocated for capacity building, the outcomes take time to transpire (Moscardo, 2005). Due to some limitation associated to rural communities, particularly economic and socio-cultural aspects, it is appropriate to expect that donor or state agencies may have to take a long time to develop a community in term of capacity building. The question is whether donor or state agencies are willing to venture into capacity building partnership with the local people when they know it would take a long time thus imminent failure. 


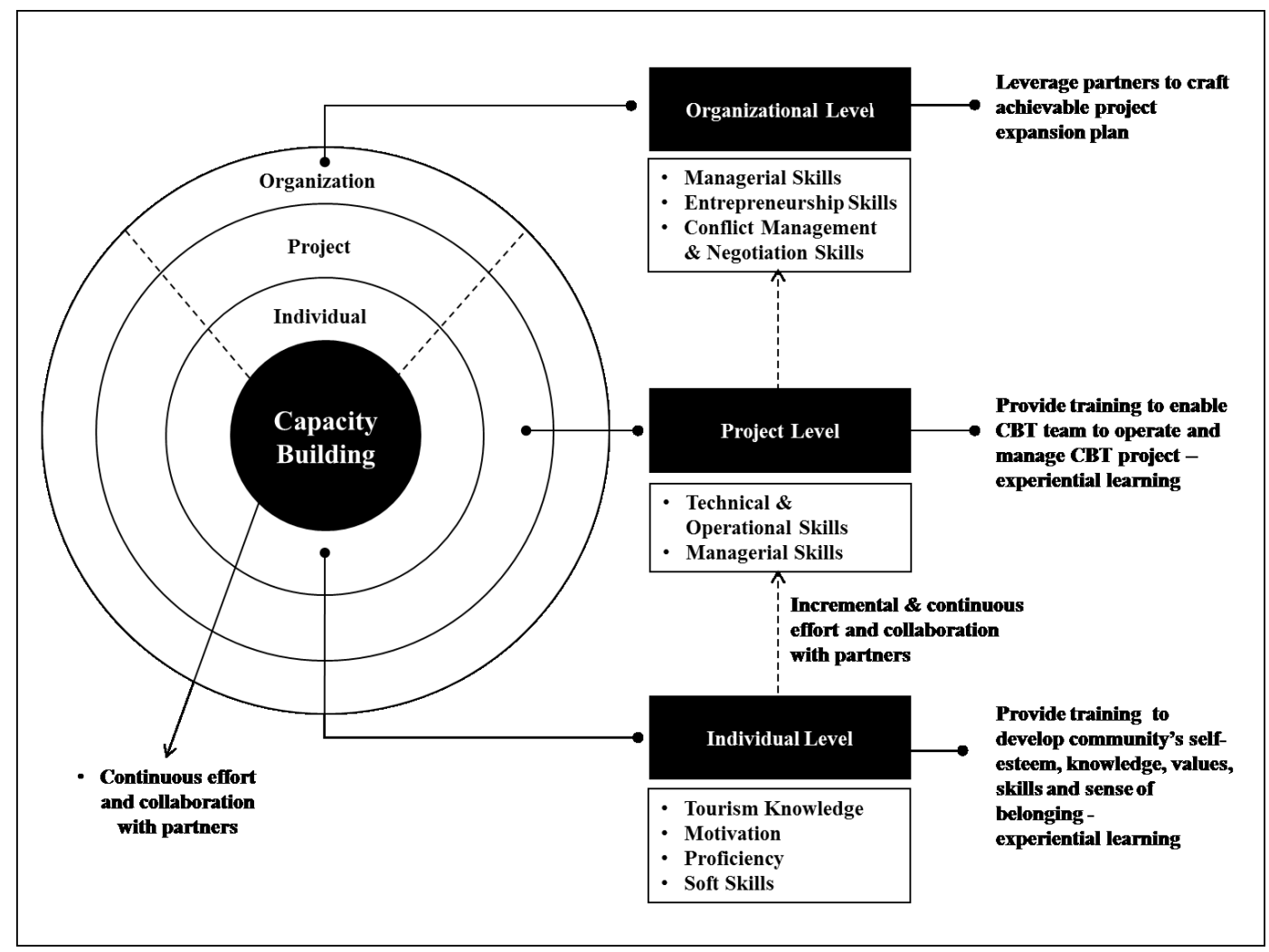

Fig. 2.Main components of capacity building programme

Source: Researcher, 2014

\section{Local Participation}

Literature suggests that the sustainability of CBT project is associated with many factors; one of them is local community's participation in the project. The finding of this study supports the claim because this study reveals that sustainability of CBT project in BatuPuteh has much to do with the willingness of the local community to get involved directly and indirectly in the CBT programme.

Given that the majority of CBT projects initiated by international donors/NGOs are driven by the conservation agenda, the economic performance or livelihood of the local communities are often not given adequate attention (Hamzah, 2010; Butcher 2007). However, MWH has proven that conservation-based CBT project can generate substantial economic benefits for the local people. At $\mathrm{MWH}$, an employee who earned a monthly income of RM460 in the 1990s was earning RM2000 a month in 2013.Over the years, the amount and number of recipients of CBT income has continuously increased. This was the main reason why local people continue to be supportive of CBT activities at MWH.

Another interesting finding that contributes to the understanding of local participation is motivation. In the case of MWH, the motivation of the local community particularly the pioneers to establish a CBT project in 1997 were intrinsically driven. The motivation to participate in CBT stemmed from shared values and similar life experience. The economic difficulties faced by the local people in the 1990s were part of the daily dialogue that the local youths became aware of the hardship that their community was facing. 
Understandably, the youths of this close-knit community that is bound by blood ties and marriage, and formal and informal social hierarchical structures was hooked to the sense of responsibility to improve the livelihood of the local community. This sense of responsibility later transpired in a CBT project. Fig. 3.shows the types of local community's participation in CBT project.

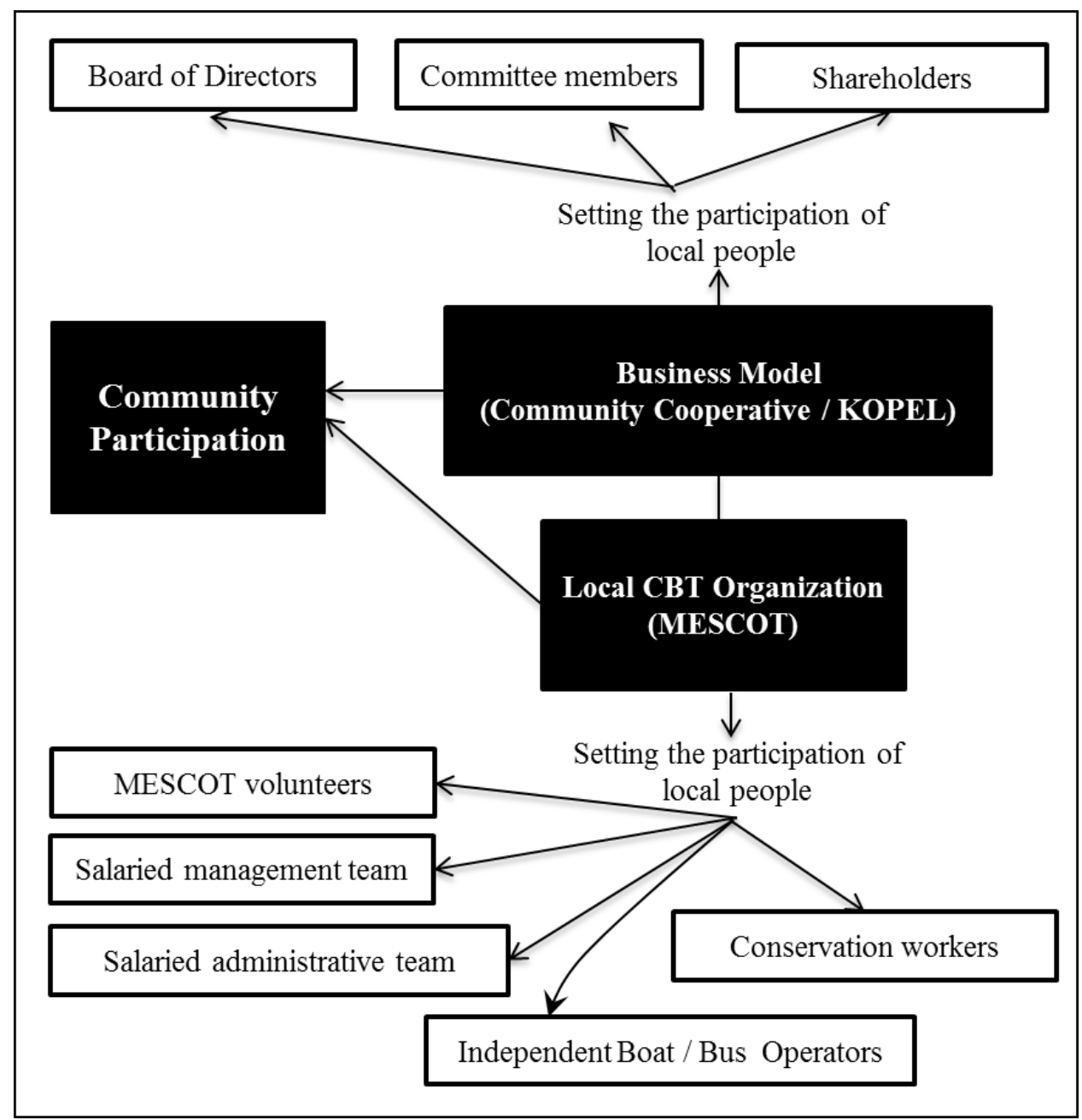

Fig. 3. Types of local community's participation in CBT project

\section{Effective Partnership}

Partnership with external agencies has commonly been instrumental in the early stage of CBT development (Hockings, et. al., 2000). Hence, developing a strong partnership with state agencies, donor agencies, and tour operators would help mitigate problems that may arise along the supply-demand value chain such as lack of knowledge and skills, lack of capital, and lack of tourist supply.

A lot of lessons on partnership can be learnt from MWH. Firstly, donor agencies are usually more responsive compared to government agencies in helping to establish CBT project. Due to flexibility in organizational procedures NGOs would be able to respond to 
financial, technical and advisory needs of local communities at a much faster rate compared to government agencies. However, sometimes these forms of supports especially financial assistance are not sustainable because they are tied to funding 'timeframe'. Seed fund is usually adequate to carry out only during preliminary research or initial groundwork, but not the subsequent development activities that demand larger amount of money.

Secondly, efforts to establish partnership with relevant parties may be hampered by historically strained relationship between the local community and external agencies. MWH faced this problem with the forestry state agency. In the attempt to enforce conservation policy, the latter restricted entry into the jungles which has been a source of livelihood for the local people. What ensued was illegal entry by the local people into the forested areas, which in turn compelled the authorities to take action against these offenders, and created further detestation on both sides. However, this issue was finally resolved when a mediator was brought in to facilitate communication between both parties. Thirdly, establishing amicable partnership that pivots on national agenda to turn a forested area into a protected area is a formidable task for state agencies and demands adequate enforcement capacity. A forested area can be gazetted but its enforcement is more difficult to translate on the ground. Some major barriers to enforce conservation policy usually come from the enforcement agencies that are often shorthanded with manpower to cover a large area. This usually gives the local community, who has an upper hand in terms of knowledge about their forest and escape routes, the opportunities to continue entering the forest illegally without being caught by the enforcement unit. Another barrier towards effective implementation of protected area is the lack of resources to finance expenses related to enforcement activities. The distance of the enforcement unit base that is far from the protected area requires substantial logistics and monetary support to pay for fuel and salary for over-time / outstation forestry staff.

Fourthly, conservation effort is difficult when there is little 'buy-in' from the local community; to them it makes little sense how protecting a forest can save humankind when their own livelihoods are at stake. Preserving biodiversity becomes a mockery for its superiority over preserving community's livelihood. Trust in external agencies and their conservation effort is compromised unless the local community can see the substitutes for their lost sources of incomes. However, many cases have shown that gradually, locals' trust can be reinstalled when the local people can see that there is a synergy between the conservation and benefits distribution to the local community. However, overtime many agencies have realized that the interface from non-protected to protected forest can be expedited, and conflict between agency and local community can be minimized through community forestry, as evident in BatuPuteh.

Finally, establishing strong and dynamic partnerships with other key stakeholders are essential in moving up CBT along the value chain (Hamzah\&Khalifah 2009). Such partnerships will pave the way for CBT to gradually become a mainstream rather than remain a niche tourism product. Partnership is essential in building the capacity of the rural communities which often lack resources, skills and knowledge to adapt to the changing economic landscape. Prior to establishing a partnership, the first impetus towards change should come from the community itself, not from an external organization. This demonstrates that the community is ready to embrace change because learning and capacity building have been proven to take place effectively when the local community is ready. Partners who are willing to commit to the partnership have to be true to the engagement and they have to address the local community's needs and concerns. 
Of late, more agencies, public or private are gradually learning and accepting that the approach to develop the rural community has to change. While some policies and systems may be rigid, there is room for innovative partnership that allows flexibility for the benefit of the local community. Stability in partnership is needed in order to create real change and therefore partnership has to be sustainable until the job is completed. In a partnership, emphasis should be placed on promoting sustainable ecological co-existence through engagement with local communities, government, donor agencies, the general public, and industry. In the process, it is imperative to build meaningful and effective partnerships and collaborations that are transformative yet able to balance the needs of all stakeholders. In short, when partnership involves a local community, the wisdom should come from the ground because the local community with their indigenous wisdom can expedite learning. It is more organic compared to stipulating what the community needs to do base on what outsiders viewed as good for them.

\section{CONCLUSION}

Any community involved in CBT would have the upper hand to plan, strategize, monitor, and evaluate their CBT programmeif they know and understand the CSF of CBT. Subsequently, they would be better-able to plan and strategize actions to develop the programme at an appropriate juncture throughout the CBT life cycle. In essence this shares several critical success factors that are instrumental in ensuring that a conservation-based CBT project such as MWH is economically successful. The critical success factors for MWH have been modelled by investigating and linking their achievements to either exogenous or endogenous factors. Based on the findings, the critical success factors could be presented in a temporal form, meaning that each factor occurs at a particular stage of the development path of MWH. Motivation to establish a CBT project is paramount because it gets the project going. However, community participation will continue so long the community get what they expected from the project. Where critical factor is concerned, each factor acts as a catalyst or trigger for the next stage of development or evolution. Fig. 4.shows the framework for CSF of CBT project based on MWH experience. 


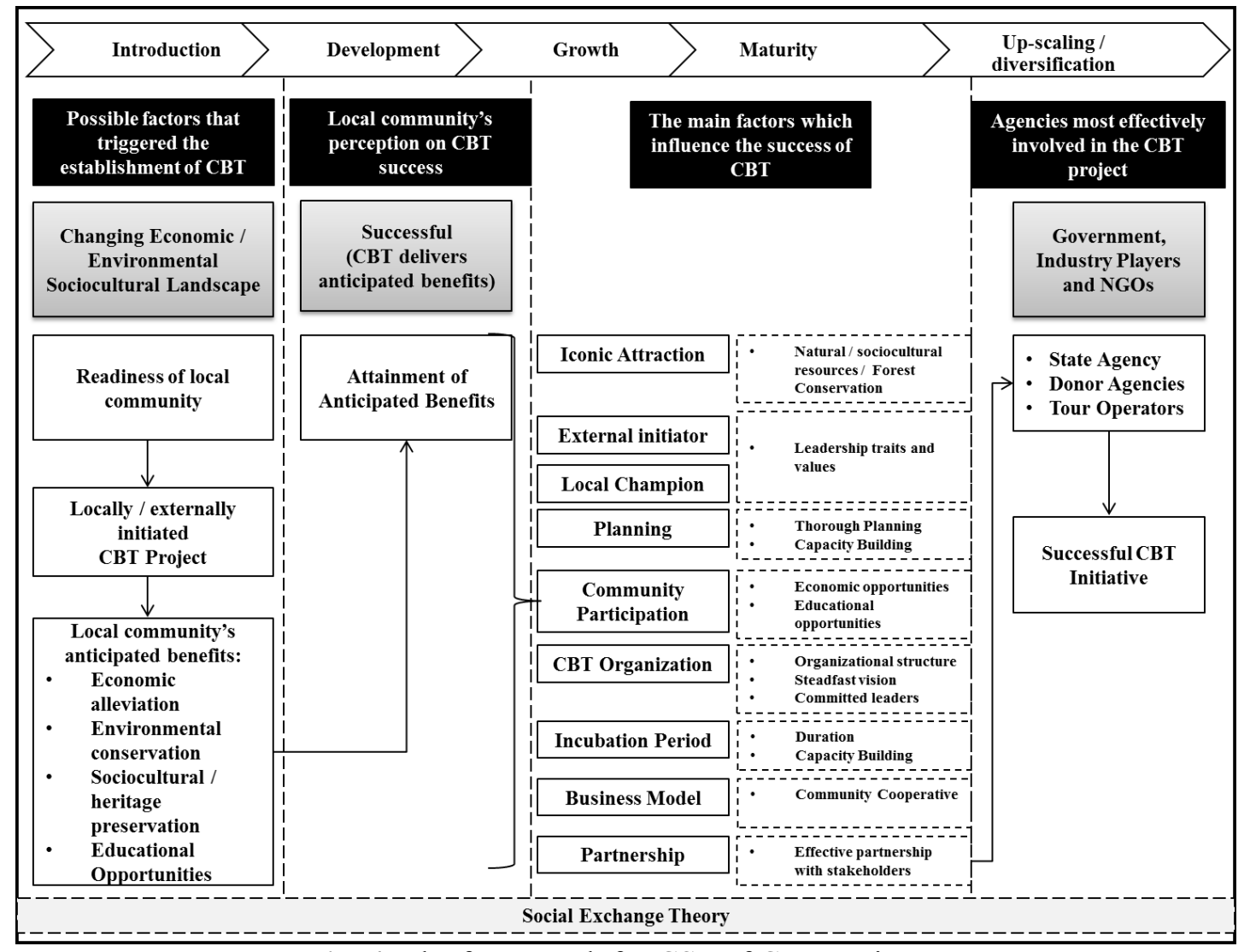

Fig. 4. The framework for CSF of CBT project

Source: Researcher, 2014

\section{REFERENCES}

1. Baromey, N., Rith, S., and Yokohari, M. (2011). Enhancing Sustainability Through the Building of Capabilities: Analysis of Community-Based Ecotourism Development in Cambodian Protected Areas. Proceedings of the $3^{\text {rd }}$ World Ecotourism Conference. 3-5 October. Sihanoukville, Cambodia: 1-19.

2. Belsky, J. (1999). Misrepresenting Communities: The Politics of Community Based Rural Ecotourism in Gales Point Manatee, Belize. Rural Sociology, 64(4): 641-666.

3. Blackstock, K. (2005). A Critical Look at Community-based Tourism. Community Development Journal, 40 (1): 39-49.

4. Briedenhann, J. and Wickens, E. (2004). Community Involvement in Tourism Development: White Elephant or Empowerment? In Weber, S. and Tomljenovic, R. (Eds.), is Reinventing a Tourism Destination: Facing the challenge (pp. 167-177). Institute for Tourism Zagreb: Croatia.

5. Clauzel, S. (2001). Community-based Tourism Policy in the Windward Islands. Paper prepared for a Seminar on policy requirements from community-based tourism in the Windward Islands, St. Lucia, West Indies, CANARI.

6. Forstner, K. (2004). Community ventures and access to markets: The role of intermediaries in marketing rural tourism products. Development Policy Review, 22, 497-514. 
7. Ghasemi, M. and Hamzah, A. (2010). An Evaluation of the Role and Performance of Ngos in Community-Based Ecotourism at Ulu Geroh, Gopeng, Malaysia. In: Lim Lay Kian and Mohd Hafiz MohdHanafiah (Eds). Proceedings of the 4th Tourism Outlook and 3rd ITSA Conference.

8. Goodwin, H. and Santilli, R. (2009). Community-Based Tourism: A Success?,International Centre for Responsible Tourism (ICRT) Occasional Paper 11, University of Greenwich.

9. Goodwin, H. (2006). Measuring and Reporting the Impact of Tourism on Poverty. Cutting Edge Research in Tourism - New Directions, Challenges and Applications. School of Management, University of Surrey, UK.

10. Gunduz, L., and Hatemi-J, A. (2005). Is The Tourism-Led Growth Hypothesis Valid For Turkey? Applied Economics Letters, 12(8): 499-504.

11. Hamzah, A. and Khalifah, Z. (2009). Handbook on Community Based Tourism: How to Develop and Sustain CBT. A Project Study Submitted By Malaysia Government. APEC, Singapore.

12. Hamzah, A. (2010). When Is A Homestay Not A Homestay? Paper presented at JPBW Weekly Seminar, 30 July 2010, Faculty of Built Environment, UniversitiTeknologi Malaysia, Johor.

13. Hjalager, A-M. (1996). Tourism and the Environment: The Innovation Connection. Journal of Sustainable Tourism. 4(4): 201-218.

14. Kiss, A. (2004). Is Community-Based Ecotourism A Good Use Of Biodiversity Conservation Funds?. Trends in Ecology and Evolution. 19(5): 232-237.

15. Luck, F. (2010). Pro Poor Tourism: A Successful Tool for Development Aid - An Analysis of Lessons Learnt. Unpubslihed Degree Thesis. International Tourism Management and Consultancy (ITMC). NHTV Breda - University of Applied Sciences.

16. MacDonald, R. and Jolliffe, L. (2003). Cultural Rural Tourism: Evidence from Canada. Annals of Tourism Research, 30(2): 307-322.

17. Mitchell, J. and Muckosy, P. (2008). A Misguided Quest: Community-Based Tourism in Latin America. ODI Opinion 102. London: Overseas Development Institute.

18. Moeurn, V., Khim, L., and Sovanny, C. (2008). Good practice in Chambok Community-based ecotourism Project in Cambodia. In: Paul Steele, Neil Fernando and ManekaWeddikkara (Eds.). Poverty Reduction that Works: Experience of Scaling up Development Success, London: Earthscan.

19. Moscardo, G. 2005, Tourism Recreation Research- Peripheral Tourism Development:Challenges, Issues and Success Factors, VOL. 30(1), 2005: 27-43

20. Renard, Y. (2001). Practical Strategies for Pro-Poor Tourism: A Case Study of the St. Lucia Heritage Tourism Programme. Pro-poor Tourism Working Paper No. 7 for the Centre for Responsible Tourism at the University of Greenwich (CRT), International Institute for Environment and Development (IIED) and Overseas Development Institute (ODI). Retrieved from http://www.propoortourism.org.uk/ ppt pubs workingpapers.html

21. Sakala, R. S. S. (2004). A Research Report - Towards Establishing Sustainability Of Community Based Development Projects With Special Reference To ChisankaneCommunity Project. St. Clements University. Retrieved from http:/www.stclements.edu/grad/gradsaka.pdf

22. Sharpley, R. (2002) The Challenges of Economic Diversification through Tourism: The Case of Abu Dhabi. International Journal of Tourism Research, 4(3): 221-235. 
23. Tooman, A. L. (1997). Applications of the Life-cycle Model in Tourism. Annals of Tourism Research. 24(1): 214-234.

24. Tooman, A. L. (1997). Tourism and Development, Journal of Travel Research, 35: 3340.

25. Vignati, F., 2009. Value Chain Analysis as a Kick Off for Tourism Destination Development in Maputo City. International Conference on Sustainable Tourism in Developing Countries 